qüências da falência perante a jurisdição local. Outro fator também importante é como vai terminar a relação jurídica estabelecida. Quero fechar apenas com um pensamento para vós. O dr. El Khosheri sugeriu que os negócios deveriam ser separados da política e eu acredito e estou de acordo com ele. Eu fico pensando como negociantes e advogados podem construir uma ponte entre o Brasil e os EUA e entre todos nós e o resto do mundo, com o que se providenciará uma base de entendimento que suple- mentará aquele que os nossos governos estão tentando construir. Por último quero contar-lhes uma experiência que tive recentemente numa conferência relativa à China. Tivemos dois dias de arrastadas discussões legais durante as quais alguém perguntou a um dos participantes chineses qual era o segredo do êxito comercial conseguido pela China. Ele respondeu e eu cito: "Paciência, confiança e amizade". Eu acho que se adotarmos estas qualidades, teremos êxito.

\title{
Arrendamento mercantil
}

Luiz Alberto Americano, procurador da Procuradoria Geral da Fazenda Nacional.

Gostaria de falar algumas palavras sobre um tipo de contrato que está entrando muito em moda entre nós - o de leasing - , para o qual existe um termo bem nosso chamado arrendamento mercantil. $\mathrm{O}$ arrendamento mercantil ou leasing está assumindo entre nós certa importância e tende a se tornar cada vez mais importante. A bibliografia brasileira sobre a matéria, mais recente, é muito precária e há alguns poucos trabalhos, mas realmente nós estamos carecendo de um trabalho mais profundo sobre o assunto que vem revestido de novas características. $\mathrm{O}$ arrendamento mercantil pode englobar, com este nome ou com o nome de leasing, ou seja, suponhamos: eu sou uma companhia de aviação e quero aumentar a minha frota. Então, eu arrendo um avião sob determinadas condições de uso, através do contrato de leasing. É uma operação que o leasing abrange. Mas o leasing abrange também uma outra operação que é, vamos dizer assim, um financiamento garantido, disfarçado com as roupas do leasing. Eisto ocorre, vamos supor, eu que sou o proprietário da aeronave e preciso de dinheiro para o meu giro de negócios. Então vendo o avião para uma
Luiz Alberto Americano

instituição financeira e esta instituição me aluga o avião. Aí então nós vemos que o leasing pode também abranger esta operação de financiamento garantido.

Insisto em falar na garantia porque, através dessa segunda modalidade de leasing nós podemos quebrar, em detrimento dos credores do devedor a regra de igualdade de preferência nos créditos. Um deles terá um crédito de maneira real. Isso é importante quando nós pensamos nos contratos internacionais de leasing; uma companhia que assim proceder e tiver outros contratos de leasing poderá, indiretamente, estar quebrando a regra pari passu, de preferência nos créditos.

E há um terceiro aspecto do leasing que eu gostaria de mencionar, porque eu gostaria de ouvir do colega Truman Bidwell, que pode nos colocar a par das úteis informações, porque nós só estamos vendo o leasing como maneira de importar, mas nós podemos utilizar o leasing como maneira de exportar.

\section{Arrendamento mercantil}

Truman Bidwell, advogado militante em Nova York, na área de direito internacional.

É verdade que em meu país, têm-se duas formas diferentes de leasing, este é um tópico acerca do qual os advogados americanos levam dias em
Truman Bidwell

reuniões tentando aprender uns com os outros, pois se trata de uma área terrivelmente complexa e esotérica. Sem tentar instruí-los numa coisa que pou- 
cos advogados americanos conhecem, permitamme apenas explicar-Ihes as diferenças e um possível uso potencial em ligação com o financiamento das vossas exportações.

Temos a forma tradicional daquilo que poderíamos chamar de bolsa de venda e arrendamento, pela qual alguém que possui bens de base, por exemplo, uma aeronave, e precisa de dinheiro, vende essa aeronave a uma instituição financeira por meio de um lease, que dará ao adquirente uma margem de lucro. Trata-se na verdade de um empréstimo disfarçado. Isso tem conseqüências na carteira de empréstimos no caso de se estar representando um cliente que já esgotou o seu crédito, pois, embora se designe como lease, considera-se para muitos efeitos um financiamento. Isso porá o comprador do bem, o avião no nosso caso, numa posição potencialmente melhor do que a dos outros credores, visto que o dito bem é agora possuído pela instituição financeira. No caso de uma insolvência ou de um arresto bancário aquele virá exigir que the "dêem o seu avião", o que constituirá por certo problemas para qualquer concordata.

A segunda espécie de financiamento, que é relativamente recente no meu país é o chamado financiamento-lease. Um financiamento-lease é um financiamento concebido para tirar vantagem dos benefícios fiscais concedidos aos possuidores de bens de base nos EUA. Em poucas palavras, aqueles benefícios fiscais são um crédito fiscal de investimento igual a $10 \%$ do valor da nota fiscal. Eu falei em crédito: é um dólar por dólar de vantagem por conta dos impostos. Segue-se então um acelerado sistema de depreciação, de modo que, por exemplo, um avião com uma duração normal de 25 anos, fica sem valor ao fim de cinco. Como se vê, isso pode ter um impacto dramático na fluidez de caixa da companhia possuidora do bem. Como poderá agora usálo para auxiliar suas exportações? Há um meio de providenciar financiamento barato para quem precisa equipamento de base mas que não pode utilizar os benefícios fiscais a ele associados. Os típicos usuários são entidades que utilizam quantidades de equipamento pesado, como companhia de aviação, vias férreas, empresas de navegação, que podem estar fazendo bastante dinheiro, mas que, por causa da depreciação e outros benefícios fiscais associados com a propriedade do equipamento, não podem auferir os ditos benefícios fiscais. Também se usa isso em relação a itens bem menores; completei recentemente uma transação envolvendo a importação de coberturas, de valor entre oitenta a cem mil dólares, destinadas a fazendeiros nos EUA, as quais foram financiadas em lease. A operação pode ser esquematizada assim: vamos supor que pretendemos vender nos EUA um determinado objeto e que se quer providenciar financiamento barato para os usuários. Vamos ter agora, é claro, que pedir emprestada uma parte do preço de compra e isso poderá obter-se por crédito de financiamento ou outra forma usada pelo nosso próprio banco, ou por empréstimo comercial direto. O saldo do preço de compra, geralmente entre 20 a $40 \%$ virá da outra instituição financeira que compra o material. Isso proporciona ao usuário do objeto um financiamento de $100 \%$. Ele não entra com qualquer participação. A instituição comercial que adquire o material arrenda-o ao usuário por um contrato que durará consoante a vida útil do mesmo. Para um avião 747 será de 22 a 24 anos. Os pagamentos das locações são, tipicamente, apenas suficientes para liquidar o débito referente à aquisição do material, o dono deste, ou seja, na nossa linguagem, o investidor da participação, retira o seu lucro dos benefícios fiscais postos à sua disposição. E como fica mais barato para o usuário? Fica mais barato porque parte dos benefícios fiscais passam para ele. Isso agora já é uma técnica bem-conhecida e estou certo de que a Varig a usa sempre na aquisição da sua frota e eu já fiz financiamentos desse tipo com vários outros países da América do Sul. Mas se, por exemplo, uma companhia brasileira tiver negócios nos EUA e for, portanto, um contribuinte aí, pode aproveitar e providenciar o financiamento de sua participação como qualquer outro investidor norteamericano. Essa forma de financiamento é, sobretudo, usada nos EUA, embora também a utilizem no estrangeiro. A diferença em usá-la no estrangeiro é que ela ai é ligeiramente menos favorável, porque o crédito pela taxa de investimento só é obtenível para objetos que sejam usados nos EUA. No entanto, esses objetos podem vir de qualquer outro lugar sem precisarem de ser fabricados neste país. Basicamente, na transação típica, o do avião ou de outro material de base reduz o seu empréstimo em cerca de $4 \%$ e, portanto, se ele havia de pagar, vamos dizer, $10 \%$ de taxa de juros, o efetivo custo do dinheiro para ele com este financiamento descerá para $6 \%$.

Ainda existem outras formas mais esotéricas nos EUA e na Inglaterra, mas acho que isso está fora da finalidade em vista. Se alguém estiver realmente interessado no assunto, terei o maior gosto em responder às perguntas que quiserem ou em conversar depois desta reunião, ou mesmo em mandar algum material que tenha disponível. 


\section{Arrendamento mercantil}

Peter Koenz, representante-residente, no Brasil, do Programa das Nações Unidas para o

Desenvolvimento - PNUD.

Peter Koenz

Apraz-me este assunto trazido pelo professor Truman Bidwell e por ter havido pelo menos um princípio de discussão do mesmo. Ele merece, talvez no futuro, uma maior explanação, mas a experiência mostra, desde já, que para além da motivação original do financiamento lease, que eram essencialmente os impostos, outros objetivos existem e podem ser alcançados, como o de isolar ou alhear o vendedor, uma companhia brasileira, por exemplo, dos riscos políticos ou não-comerciais em vários países estrangeiros. A tal respeito, tudo o que posso relatar é experiência com companhias coreanas, pois a Coréia é, talvez, dentre os paíseś recém-industrializados, o que vem usando mais ativamente o leasing, interna e externamente. Julgo que a experiência tem sido bem positiva e, no contexto de futuras operações externas do Brasil, poderá considerar-se o leasing pa-

ra objetos móveis - aviões, veículos, equipamento para construção - e até mesmo para coisas fixas. Há uma crescente tendência nos EUA, sobretudo por razões fiscais, mas podem existir razões que transcendam a motivação fiscal, permitindo o progressivo financiamento leasing mesmo para instalações fixas ou cauções de tesouraria. Acho que isto é um assunto que merece mais do que os dez minutos finais de um seminário e que seria bom, talvez, considerá-lo em qualquer ocasião em conjunto com a nova postura do Brasil como exportador de toda espécie de equipamentos, da Mendes Júnior ou de firmas de engenharia, os quais expõem algum do seu equipamento de construção em áreas onde não tem controle e das quais possuem perfunctório conhecimento.

\section{Arrendamento mercantil}

Paulo Tarso Flexa de Lima, embaixador, presidente da Mesa.
Paulo Tarso Flexa de Lima
Talvez eu deva acrescentar alguns comentários. O primeiro sobre a criatividade dos nossos exportadores e autoridades governamentais ao adotarem a fórmula chamada lease-back, que é realmente uma operação leasing, uma operação de leasing externo mas em que o bem de base não sai do país. Tem vindo a ser cada vez mais utilizada no Brasil com os equipamentos de petróleo, os quais são aqui fabricados e teoricamente exportados para um mercado financeiro. Neste, a companhia de leasing reexporta-os teoricamente para o Brasil, fazendo um leasing sobre eles. É uma forma que vem sendo usada num crescendo entre nós, sendo que é muito financial na sua concepção. 